
\title{
3 Research Square \\ IL-21 Enhances the Immune Protection Induced by the Vibrio Vulnificus Hemolysin A Protein
}

\section{Ke-Na Sun}

the 960th Hospital of the PLA

\section{Fei Huang}

the 960th Hospital of the PLA

\section{Ming-Yi Wang}

Weihai Municipal Hospital affiliated to Dalian Medical University

Jing Wu

the 960th Hospital of the PLA

Cheng-Jin Hu

the 960th Hospital of the PLA

Xiao-Fei Liu ( $\square$ liuxiaofei0401@163.com )

the 960th Hospital of the PLA https://orcid.org/0000-0002-4921-2544

\section{Research Article}

Keywords: Vibrio vulnificus, hemolysin A, IL-21, immune protection

Posted Date: August 25th, 2021

DOI: https://doi.org/10.21203/rs.3.rs-832004/v1

License: (c) (1) This work is licensed under a Creative Commons Attribution 4.0 International License. Read Full License

Version of Record: A version of this preprint was published at Inflammation on February 7th, 2022. See the published version at https://doi.org/10.1007/s10753-022-01632-1. 


\section{Abstract}

We previously reported that the Vibrio vulnificus hemolysin A (VvhA) protein elicited good immune protection and could effectively control $V$. vulnificus infection in mice. However, its molecular mechanism remains unknown. In this study, we found that IL-21 enhances immune protection by inducing a Tfh-cell and germinal center (GC) B-cell response. We used RNA-seq and identified 10 upregulated and 30 downregulated genes that were involved in IL-21-upregulated protection. We also performed Gene Ontology (GO) analysis and pathway analysis of these differentially expressed genes. Our findings indicate that IL-21 can enhance the immune protection effect of VvhA protein and may serve as a novel strategy for enhancing the immune protection effect of protein vaccines.

\section{Introduction}

Vibrio vulnificus ( $V$. vulnificus) is a marine gram-negative bacterium that is responsible for fatal septicemia and necrotizing wound infections through either the ingestion of contaminated seafood or wound infections in humans [1-3]. The high mortality and severity of infection emphasize the need for effective approaches to prevent $V$. vulnificus infection. Although the pathogenic mechanism of $V$. vulnificus infection has not been fully delineated, several of its potential virulence factors have been extensively described, such as hemolysin, toxic cytokines, proteolytic enzymes, flagella, and phospholipase A [4-6]. Hemolysin is a very powerful virulence factor of $V$. vulnificus and is a likely candidate for the pathogenesis of $V$. vulnificus infections [7]. $V$. vulnificus hemolysin A (VvhA) toxin has cytolytic and hemolytic activity and is responsible for the death of host cells during the infection $[8,9]$. This toxin attaches to the host cell membrane to induce hemolysis by forming small ion permeable pores via colloidal osmotic shock $[10,11]$. Moreover, VvhA may contribute to bacterial invasion from the intestine to the bloodstream and other organs; furthermore, deletion of VvhA from $V$. vulnificus has been shown to attenuate its virulence [12].

In our previous study, we expressed and purified recombinant VvhA protein. Our results revealed that the VvhA protein elicited a good immune protection effect and could effectively control $V$. vulnificus infection. We also found that the protective mechanism of VvhA protein after immunization is closely related to $T$ follicular helper (Tfh) cells and GC B cells [13]. Tfh cells have recently emerged as a separate subset of CD4 ${ }^{+} T$ helper cells [14]. The major function of Tfh cells is to aid in B-cell activation and antibody production during humoral immune responses, specifically via interactions between molecules on the surface of Tfh cells and receptors or ligands located on the surface of B cells [15]. We also found that serum IL-21 levels were dramatically increased in VvhA-immunized mice. IL-21 is a cytokine that is preferentially expressed by Tfh cells and serves as an important regulator of humoral responses by directly regulating B-cell proliferation and class switching [16-18].

Therefore, IL-21 likely plays an important role in the immune protection of the VvhA protein. In the present study, we aimed primarily to investigate the protective effects of VvhA protein immunized mice via the 
regulation of IL-21. Next, we explored the possible regulatory mechanisms involved. We expected to find a more effective strategy to enhance the protective effect of the VvhA protein.

\section{Materials And Methods}

\section{Bacterial strains and growth conditions}

The $V$. vulnificus M06-24/O strain, kindly provided by Professor Sang Ho Choi, Seoul National University, Seoul, South Korea, was originally isolated from a patient with septicemia. The strain was selected on thiosulfate citrate bile salt agar plates and grown in alkaline peptone water (APW) supplemented with $2 \%$ $(\mathrm{w} / \mathrm{v}) \mathrm{NaCl}$ at $37^{\circ} \mathrm{C}$ for $16 \mathrm{~h}$. The bacterial cells were centrifuged at $2500 \times g$ for $5 \mathrm{~min}$ and then resuspended in APW. The concentration of bacteria suspended in APW was adjusted to $2 \times 10^{6}$ colonyforming units (CFU)/mL prior to infection.

\section{Expression and purification of VvhA protein}

VvhA was expressed and purified as described previously [13]. Briefly, vvhA DNA and pET28a (+) were digested with same enzymes that were recovered for ligation. Then, E. coil Rosetta (DE3) transformed with pET28a (+)- $v v h A$ was cultured in Luria-Bertani medium containing ampicillin $(100 \mathrm{mg} / \mathrm{L})$ for $2 \mathrm{~h}$ and induced with isopropyl $\beta$-d-1-thiogalactopyranoside $(1.0 \mathrm{mmol} / \mathrm{L})$ at $30^{\circ} \mathrm{C}$ for $4 \mathrm{~h}$. Bacterial cells were harvested by centrifugation, and the total cell protein was obtained by boiling; next, sodium dodecyl sulfate-polyacrylamide gel electrophoresis was performed. The protein bands were visualized by Coomassie blue staining and confirmed by western blot analysis using anti-His tag antibodies. Finally, recombinant VvhA fusion protein was affinity-purified from total cell protein using Ni-nitrilotriacetic acid resin.

\section{Animal experiments}

All animal experiments were approved by the Animal Ethics and Experimental Committee of the $960^{\text {th }}$ Hospital of the PLA Joint Logistics Support Force, Ji'nan, China. Six- to eight-week-old specific-pathogen free female BALB/c mice weighing approximately $20 \mathrm{~g}$ were purchased from the Center of Experimental Animals at Shandong University (Ji'nan, China). Female BALB/c mice were immunized by subcutaneous injection with $100 \mu \mathrm{g}$ of purified recombinant VvhA fusion protein mixed with Freund's complete adjuvant, followed by immunization on days 7, 14, and 21 with $100 \mu \mathrm{g}$ of purified recombinant VvhA fusion protein emulsified in $0.5 \mathrm{~mL}$ of Freund's incomplete adjuvant. Next, $50 \mu \mathrm{g}$ of purified recombinant VvhA fusion protein solution was administered by the intraperitoneal route on day 25 .

\section{Treatment of mice with IL-21 or IL-21 mAb}

Two days after immunization, the mice were intraperitoneally injected with $10 \mu \mathrm{g}$ of mouse IL-21 mAb (Clone 149204, rat IgG2b, R\&D Systems, Minneapolis, MN, USA) as the IL-21-downregulated group or with $0.5 \mu \mathrm{g}$ of recombinant mouse IL-21 (R \& D Systems) as the IL-21-upregulated group. Control mice 
received an equal volume of phosphate-buffered saline. The administration was repeated every 7 days until the mice were sacrificed at the indicated times.

\section{Histopathological evaluation}

The treated mice were dissected at $72 \mathrm{~h}$ after intraperitoneal injection of $V$. vulnificus, and the liver and lung tissues were collected for hematoxylin and eosin (H\&E) staining. Two pathologists performed the histopathological evaluation in a blinded fashion.

\section{Flow cytometric analysis for Tfh cells and GC B cells}

Single lymph node cell suspensions from immunized mice were gained by grinding with a sterile plunger of syringe and filtering with 70- $\mu$ m cell strainers (BD Falcon, San Jose, CA, USA). Collected cells were stained with PE-CF594-conjugated CD4 (BD Pharmingen, San Diego, CA, USA), biotin anti-mouse CD185 (CXCR5) (Biolegend, San Diego, CA, USA), PECY7-conjugated B220 (BD Pharmingen, San Diego, CA, USA), fluorescein isothiocyanate (FITC)-conjugated GL7 (BD Pharmingen, San Diego, CA, USA), and PE-Cy5.5 Streptavidin (Lifetech) for $45 \mathrm{~min}$. Then, the samples were fixed and permeabilized with eBioscience fixation/permeabilization solution (eBioscience, San Diego, CA, USA). The cells were then stained with PEconjugated Bcl-6 (BD Pharmingen, San Diego, CA, USA). After washing, the cells were resuspended in 400 $\mu \mathrm{L}$ of staining buffer and analyzed on a FC 500 Cytometer (Beckman-Coulter, Brea, CA, USA).

$\mathrm{CD} 4^{+} \mathrm{CXCR} 5^{+} \mathrm{Bcl}-6^{+} \mathrm{T}$ cells were defined as Tfh cells, and $\mathrm{B} 220^{+} \mathrm{GL}-7^{+} \mathrm{Bcl}-6^{+}$cells were defined as $\mathrm{GC} \mathrm{B}$ cells. Data were analyzed using CXP software (Beckman-Coulter, Brea, CA, USA).

\section{RNA sequencing}

Total RNA of the samples was isolated using an RNeasy Mini kit (Qiagen, Germany). Paired-end libraries were synthesized using a TruSeq ${ }^{\text {TM }}$ RNA sample preparation kit (Illumina, USA) according to the manufacturer's instructions. Purified libraries were quantified by a Qubit ${ }^{\circledR} 2.0$ Fluorometer (Life Technologies, USA) and validated by an Agilent 2100 bioanalyzer (Agilent Technologies, USA) to confirm the insert size and calculate the molar concentration. The library construction and sequencing were performed at the ShangHai Genminix Information Technology Co., Ltd (Shanghai, China).

\section{RT-qPCR}

Total RNA was isolated from lymph node cells using TRIzol (Invitrogen, Carlsbad, CA, USA). RNA samples were subjected to DNase treatment (Promega, Madison, WI, USA) at $37^{\circ} \mathrm{C}$ for $15 \mathrm{~min}$ and reversedtranscribed to $C D N A$ in a PrimeScript ${ }^{\mathrm{TM}} \mathrm{RT}$ reagent kit (TaKaRa, Japan). Expression levels of $C X C R 5$, TLR7, CCR5, and CCR2 were analyzed using the SYBR green RT-qPCR method on a LightCycler instrument (LightCycler 480, Roche Diagnostics, Mannheim, Germany). Table 1 lists the primers used for the RTqPCR. The thermal cycling conditions were as follows: an initial denaturation step at $94^{\circ} \mathrm{C}$ for $1 \mathrm{~min}$; followed by 40 cycles of denaturation at $95^{\circ} \mathrm{C}(5 \mathrm{~s})$, annealing at $60^{\circ} \mathrm{C}(5 \mathrm{~s})$, and extension at $72^{\circ} \mathrm{C}(30 \mathrm{~s})$. Fluorescence data were collected at the end of the $60^{\circ} \mathrm{C}$ primer annealing step for 40 amplification cycles. 
The specificity of the amplification product was verified by melting curve analysis after the process was complete. Gene expression was normalized against that of mouse GAPDH, and the relative gene expression was expressed as "fold change" using the $2^{-\Delta \Delta C t}$ method.

\section{Statistical analysis}

Data were expressed as means \pm standard deviation (SD). Student's $t$ test was used to analyze the differences between the two groups, but when the variances differed, the Mann-Whitney $U$ test was used. A $P$ value $<0.05$ was considered statistically significant.

\section{Results}

\section{Survival rate of mice after IL-21 regulation}

To investigate the function of IL-21 in VvhA protein immunization, mice were intraperitoneally injected with IL-21 mAb or recombinant IL-21. After intraperitoneal injection of $V$. vulnificus for $72 \mathrm{~h}$, the survival rates of the mice were monitored. As shown in Figure 1, four mice died within $36 \mathrm{~h}$ of treatment with IL-21 $\mathrm{mAb}$, and the survival rate of the mice was $33.3 \%$. One mouse died within $30 \mathrm{~h}$ after $\mathrm{V}$. vulnificus infection in the VvhA immunization group, whereas all the mice in the IL-21-upregulated group survived. These results suggested that IL-21 enhanced the protective effect after recombinant VvhA protein immunization.

\section{Histopathological evaluation}

To explore the effect of IL-21 regulation on tissues and organs, liver and lung tissues with severe injury after $V$. vulnificus infection were sectioned to perform H\&E staining. The results showed that liver injury was the most serious in mice after they were injected with IL-21 mAb, and this liver injury was accompanied with central venous congestion, severe osteoporosis, swelling, necrosis, and inflammatory cell infiltration in hepatocytes (Figure 2a). Simultaneously, the alveolar walls were severely thickened, the alveolar cavities disappeared, and a large number of inflammatory cells were infiltrated in the lungs (Figure $2 b$ ). The VvhA immunization group showed only slight changes in inflammation, whereas there were no significant changes in the IL-21-upregulated group both in liver and lung tissues. These data implied that improving the function of IL-21 can enhance the immune protection effect of VvhA protein and reduce the damage caused by $V$. vulnificus infection in mice.

\section{IL-21 can activate Tfh cells and GC B cells in mice}

To further explore the immune protective mechanism of IL-21, the ratio of Tfh cells and GC B cells was analyzed using flow cytometry in mouse lymph nodes treated with IL-21. The results revealed a higher Tfh cell: GC B-cell ratio in the IL-21-upregulated group compared to the other two groups $(P<0.05$, Figure 3 ), suggesting that IL-21 could activate Tfh cells and GC B cells in VvhA-immunized mice.

\section{Differential genes regulated by IL-21}


To gain insights into the mechanism of IL-21-induced protection, we performed RNA-seq to identify transcriptional targets of IL-21 upregulated in VvhA-immunized mice. After data analysis, the mRNA expression was clustered using Cluster 3.0 software. IL-21 treatment was found to promote the upregulation of 1195 genes and the downregulation of 2489 genes compared with the control group. Among these regulated genes, 40 were screened by the threshold of 2.0 -fold change and a $P$ value lower than 0.05 , including 10 upregulated genes and 30 downregulated genes. (Fig. 4).

\section{Gene Ontology (GO) analysis and pathway analysis of differential genes}

To further explore the function of IL-21 in gene regulation, we conducted GO analysis to identify general functional features implemented by the IL-21-upregulated group using the above-mentioned 40 genes. The threshold of significance was defined by a $P$ value $<0.05$. The highly significant GOs of 10 differentially upregulated genes included immune response, $T$ cell differentiation, and chemotaxis (Fig. $5 a$ ). The highly significant GOs of 30 differentially downregulated genes included regulation of transcription, phosphorylation, and protein phosphorylation (Fig. 5b). Kyoto Encyclopedia of Genes and Genomes pathway analysis demonstrated that the 10 upregulated genes were significantly associated with cytokine-cytokine receptor interaction, chemokine signaling pathway, and the NF-kappa B signaling pathway (Fig. 6a). The 30 downregulated genes were significantly associated with cancer, the MAPK signaling pathway, and the PI3K-Akt signaling pathway (Fig. 6b).

\section{Gene expression validation by RT-qPCR}

To confirm the results of the RNA-seq, RT-qPCR was applied to further examine the expressions of target genes. The CXCR5, TLR7, CCR5, and CCR2 genes were chosen for further analysis using GAPDH to normalize gene expression. The results showed significantly higher CXCR5, TLR7, CCR5 and CCR2 mRNA expression in the IL-21-treated group compared to the VvhA-immunized group $(P<0.05$, Fig. 7). Although these results were consistent with the RNA-seq data, a small difference was seen between two methods in terms of the degree of overexpression. This difference could be attributed to differences in sample preparation and sensitivity of the measuring method.

\section{Discussion}

Vaccines are an effective, safe, and economical measure to prevent bacterial or viral infection. Our previous study proved that the VvhA protein elicited good immune protection, and the serum levels of IL21 were dramatically increased in the VvhA-immunized mice. IL-21 plays a key role in CD ${ }^{+} \mathrm{Tfh}$ cells in regulating $B$-cell function, including antibody maturation and conversion between Ig isotypes and IgG isotypes $[19,20]$. A previous study reported that IL-21 as an immune adjuvant can significantly increase antibody quality induced by heterologous DNA-MVA prime-boost vaccine [21]; however, few reports about protein vaccines have been published. In our study, IL-21 upregulation was found to increase the survival rate of mice and reduce liver and lung tissue injury, suggesting that IL-21 could enhance the immune protection of the VvhA vaccine. 
IL-21 can promote the differentiation of $\mathrm{CD} 4^{+} \mathrm{T}$ cells into Tfh cells and is a critical regulator of $\mathrm{Tfh}$ development. In addition, the IL-21 receptor (IL-21R) is composed of heterogenous IL-21R a- and $y$-chain subunits, which are expressed on the surfaces of several types of cells, including B cells, Tfh cells, Th17 cells, and NK T cells. However, B cells are its primary target [16]. Here, to explore the immune protective mechanism of IL-21, we detected changes in the percentages of Tfh and GC B cells in mouse lymph nodes using flow cytometry. The results revealed that IL-21 upregulation could significantly increase the expression of Tfh cells and GC B cells. However, the gene and signaling pathways that are involved in IL21-mediated immune protection remain to be unknown.

Next, we further detected the changes in gene expression profiles of lymphocytes in IL-21 regulated model mice by RNA sequencing. The results showed that 10 genes including $C X C R 5, T L R 7, C C R 2$, and CCR5 were significantly upregulated, while 30 genes including $C C R 7, J A K 1$, and $C D 21 A$ were significantly downregulated. $C X C R 5$ is a surface chemokine receptor that is stably and persistently expressed in Tfh cells. After antigen stimulation, $T$ cells downregulated the expression of $C C R 7$ and upregulated the expression of CXCR5 [22]. Upregulated CXCR5 expression promotes the migration and localization of Tfh cells in the GC, where Tfh cells interact with B cells to activate B cells [23, 24].

Toll-like receptors are a class of pattern recognition receptors that play a pivotal role in bridging innate and adaptive immunity $[25,26]$. $T L R 7$, which is primarily identified as the sensor for single-stranded RNA virus during viral infections, can also be triggered by immune modifiers that share a similar structure to nucleosides during bacterial infections [27, 28]. Moreover, vaccines that are formulated with a Toll-like receptor 7 -dependent adjuvant can induce a high level and broad range of protection against $S$. aureus [29]. These findings suggest that $T L R 7$ signaling might play an important role in host innate immune response during bacterial infection.

Chemokine receptor-2 (CCR2) is a specific receptor for monocyte chemotactic protein-1 (MCP-1), which belongs to the G-protein-coupled receptor superfamily. CCR2 is a major chemokine receptor that induces monocyte/macrophage recruitment to inflammatory sites [30]. CCR5 is $\beta$-chemokine receptor that can trigger numerous types of JAK-STAT signal transduction pathways depending on cell types, and it plays a specific role in mediating antigen presentation of dendritic cells and T cell activation [31]. Here, we demonstrated that IL-21 could upregulate the expression of CCR2 and CCR5, perhaps by recruiting monocytes/macrophages to the inflammatory site or activate T cells to resist the invasion of $V$. vulnificus.

In conclusion, IL-21 can enhance the immune protection effect of VvhA protein vaccine, which may effectively control the infection of $V$. vulnificus. Exploring the potential mechanism will open up new ideas and provide new evidence for enhancing the immune protection effect of protein vaccines.

\section{Declarations}

Funding: This study was funded by the Dean Foundation (No.2021MS02) 
Conflicts of interest/Competing interests: The authors declare that they have no conflicts of interest.

Availability of data and material: The datasets used or analysed during the current study are available from the corresponding author on reasonable request.

Code availability: Not applicable.

Ethics approval: All animal experiments were approved by the Animal Ethics and Experimental Committee of the $960^{\text {th }}$ Hospital of the PLA Joint Logistics Support Force.

Consent to participate: Not applicable.

Consent for publication: Not applicable.

\section{Author contributions:}

All authors contributed to the study conception and design. Material preparation, data collection and analysis were performed by Ke-Na Sun, Fei Huang, Jing Wu and Cheng-Jin Hu. The first draft of the manuscript was written by Xiao-Fei Liu and Ming-Yi Wang and all authors commented on previous versions of the manuscript. All authors read and approved the final manuscript.

\section{Acknowledgments:}

We thank Professor Sang Ho Choi for kindly providing the V. vulnificus M06-24/O strain.

\section{References}

1. Jones MK, Oliver JD. Vibrio vulnificus: disease and pathogenesis. 2009. Infection and immunity 77:1723-1733.

2. Feldhusen F. The role of seafood in bacterial foodborne diseases. 2000. Microbes and infection / Institut Pasteur 2:1651-1660.

3. Mead PS, Slutsker L, Dietz V, McCaig LF, Bresee JS, Shapiro C, Griffin PM, Tauxe RV. 1999. Food-related illness and death in the United States. Emerging infectious diseases 5:607-625.

4. Sun J, Zheng J, Wang G, Li Y, Shen H. Apoptotic effect of Vibrio vulnificus cytolysin on A549 human lung adenocarcinoma cells. 2012. Molecular medicine reports 5:668-674.

5. Oliver JD. 2013. Vibrio vulnificus: death on the half shell. A personal journey with the pathogen and its ecology. Microbial ecology 65:793-799.

6. Horseman MA, Surani S. 2011. A comprehensive review of Vibrio vulnificus: an important cause of severe sepsis and skin and soft-tissue infection. International journal of infectious diseases : IJID : official publication of the International Society for Infectious Diseases 15:e157-166. 
7. Qin K, Fu K, Liu J, Wu C, Wang Y, Zhou L. 2019. Vibrio vulnificus cytolysin induces inflammatory responses in RAW264.7 macrophages through calcium signaling and causes inflammation in vivo. Microbial pathogenesis 137:103789.

8. Sugiyama H, Kashimoto T, Ueno S, Ehara H, Kodama T, lida T, Susa N. 2011. Relationship between localization on cellular membranes and cytotoxicity of Vibrio vulnificus hemolysin. PloS one 6:e26018.

9. Lee SE, Ryu PY, Kim SY, Kim YR, Koh JT, Kim OJ, Chung SS, Choy HE, Rhee JH. 2004. Production of Vibrio vulnificus hemolysin in vivo and its pathogenic significance. Biochemical and biophysical research communications 324:86-91.

10. Kim HR, Rho HW, Jeong MH, Park JW, Kim JS, Park BH, Kim UH, Park SD. 1993. Hemolytic mechanism of cytolysin produced from V. vulnificus. Life sciences 53:571-577.

11. Yamanaka H, Satoh T, Katsu T, Shinoda S. 1987. Mechanism of haemolysis by Vibrio vulnificus haemolysin. Journal of general microbiology 133:2859-2864.

12. Jeong HG, Satchell KJ. 2012. Additive function of Vibrio vulnificus MARTX(Vv) and VvhA cytolysins promotes rapid growth and epithelial tissue necrosis during intestinal infection. PLOS pathogens 8:e1002581.

13. Wang MY, Liu XF, Xia J, Li Y, Geng JL, Hu CJ. 2017. Vibrio vulnificus VvhA induces Th1 and Tfh cells to proliferate against Vibrio vulnificus in a mouse model of infection. Future microbiology 12:953-965.

14. Fazilleau N, Mark L, McHeyzer-Williams LJ, McHeyzer-Williams MG. 2009. Follicular helper T cells: lineage and location. Immunity 30:324-335.

15. Morita R, Schmitt N, Bentebibel SE, Ranganathan R, Bourdery L, Zurawski G, Foucat E, Dullaers M, Oh $S$, Sabzghabaei $N$ et al. 2011. Human blood CXCR5(+)CD4(+) T cells are counterparts of $T$ follicular cells and contain specific subsets that differentially support antibody secretion. Immunity 34:108-121.

16. Spolski R, Leonard WJ. 2008. Interleukin-21: basic biology and implications for cancer and autoimmunity. Annual review of immunology 26:57-79.

17. Spolski R, Kashyap M, Robinson C, Yu Z, Leonard WJ. 2008. IL-21 signaling is critical for the development of type I diabetes in the NOD mouse. Proceedings of the National Academy of Sciences of the United States of America 105:14028-14033.

18. Kuchen S, Robbins R, Sims GP, Sheng C, Phillips TM, Lipsky PE, Ettinger R. 2007. Essential role of IL21 in B cell activation, expansion, and plasma cell generation during CD4+ T cell-B cell collaboration. Journal of immunology 179:5886-5896.

19. Chen Y, Yu M, Zheng Y, Fu G, Xin G, Zhu W, Luo L, Burns R, Li QZ, Dent AL et al. 2019. CXCR5(+)PD1(+) follicular helper CD8 T cells control B cell tolerance. Nature communications 10:4415. 
20. Rasheed MA, Latner DR, Aubert RD, Gourley T, Spolski R, Davis CW, Langley WA, Ha SJ, Ye L, Sarkar $S$ et al. 2013. Interleukin-21 is a critical cytokine for the generation of virus-specific long-lived plasma cells. Journal of virology 87:7737-7746.

21. Fan W, Wan Y, Li Q. 2020. Interleukin-21 enhances the antibody avidity elicited by DNA prime and MVA boost vaccine. Cytokine 125:154814.

22. Fazilleau N, Eisenbraun MD, Malherbe L, Ebright JN, Pogue-Caley RR, McHeyzer-Williams LJ, McHeyzer-Williams MG. 2007. Lymphoid reservoirs of antigen-specific memory T helper cells. Nature immunology 8:753-761.

23. Nance JP, Belanger S, Johnston RJ, Takemori T, Crotty S. 2015. Cutting edge: T follicular helper cell differentiation is defective in the absence of Bcl6 BTB repressor domain function. Journal of immunology 194:5599-5603.

24. Crotty S. 2014. T follicular helper cell differentiation, function, and roles in disease. Immunity 41:529542.

25. Hennessy EJ, Parker AE, O'Neill LA. 2010. Targeting Toll-like receptors: emerging therapeutics? Nature reviews Drug discovery 9:293-307.

26. Liu CH, Liu H, Ge B. 2017. Innate immunity in tuberculosis: host defense vs pathogen evasion. Cellular \& molecular immunology 14:963-975.

27. Jian W, Gu L, Williams B, Feng Y, Chao W, Zou L. 2019. Toll-like Receptor 7 Contributes to Inflammation, Organ Injury, and Mortality in Murine Sepsis. Anesthesiology 131:105-118.

28. Maeda K, Akira S. 2016. TLR7 Structure: Cut in Z-Loop. Immunity 45:705-707.

29. Bagnoli F, Fontana MR, Soldaini E, Mishra RP, Fiaschi L, Cartocci E, Nardi-Dei V, Ruggiero P, Nosari S, De Falco MG et al. 2015. Vaccine composition formulated with a novel TLR7-dependent adjuvant induces high and broad protection against Staphylococcus aureus. Proceedings of the National Academy of Sciences of the United States of America 112:3680-3685.

30. Kurihara T, Warr G, Loy J, Bravo R. 1997. Defects in macrophage recruitment and host defense in mice lacking the CCR2 chemokine receptor. The Journal of experimental medicine 186:1757-1762.

31. Vangelista L, Vento S. 2017. The Expanding Therapeutic Perspective of CCR5 Blockade. Frontiers in immunology 8:1981.

\section{Tables}

Table 1. Primer sequences used for RT-qPCR 


\begin{tabular}{|c|c|}
\hline Gene & Primer Sequence \\
\hline \multirow[t]{2}{*}{ CXCR5 } & For: 5囚-ATCGTCCATGCTGTTCACGCCT-3囚 \\
\hline & Rev: 5囚-CAACCTTGGCAAAGAGGAGTTCC-3》 \\
\hline \multirow[t]{2}{*}{$T L R 7$} & For: 5囚-GTGATGCTGTGTGGTTTGTCTGG-3】 \\
\hline & Rev: 5囚-CCTTTGTGTGCTCCTGGACCTA-3】 \\
\hline \multirow[t]{2}{*}{ CCR5 } & For: 5》-GTCTACTTTCTCTTCTGGACTCC-3】 \\
\hline & Rev: 5囚-CCAAGAGTCTCTGTTGCCTGCA-3》 \\
\hline \multirow[t]{2}{*}{ CCR2 } & For: 5》-GCTGTGTTTGCCTCTCTACCAG-3】 \\
\hline & Rev: 5囚-CAAGTAGAGGCAGGATCAGGCT-3】 \\
\hline \multirow[t]{2}{*}{ GAPDH } & For: 5囚-CATCACTGCCACCCAGAAGACTG-3囚 \\
\hline & Rev: 5囚-ATGCCAGTGAGCTTCCCGTTCAG-3》 \\
\hline
\end{tabular}

CXCR5, C-X-C chemokine receptor type 5; TLR7, Toll-like receptor 7; CCR5, C-C chemokine receptor type 5; CCR2, C-C chemokine receptor type 2; GAPDH, glyceraldehyde-3-phosphate dehydrogenase.

\section{Figures}

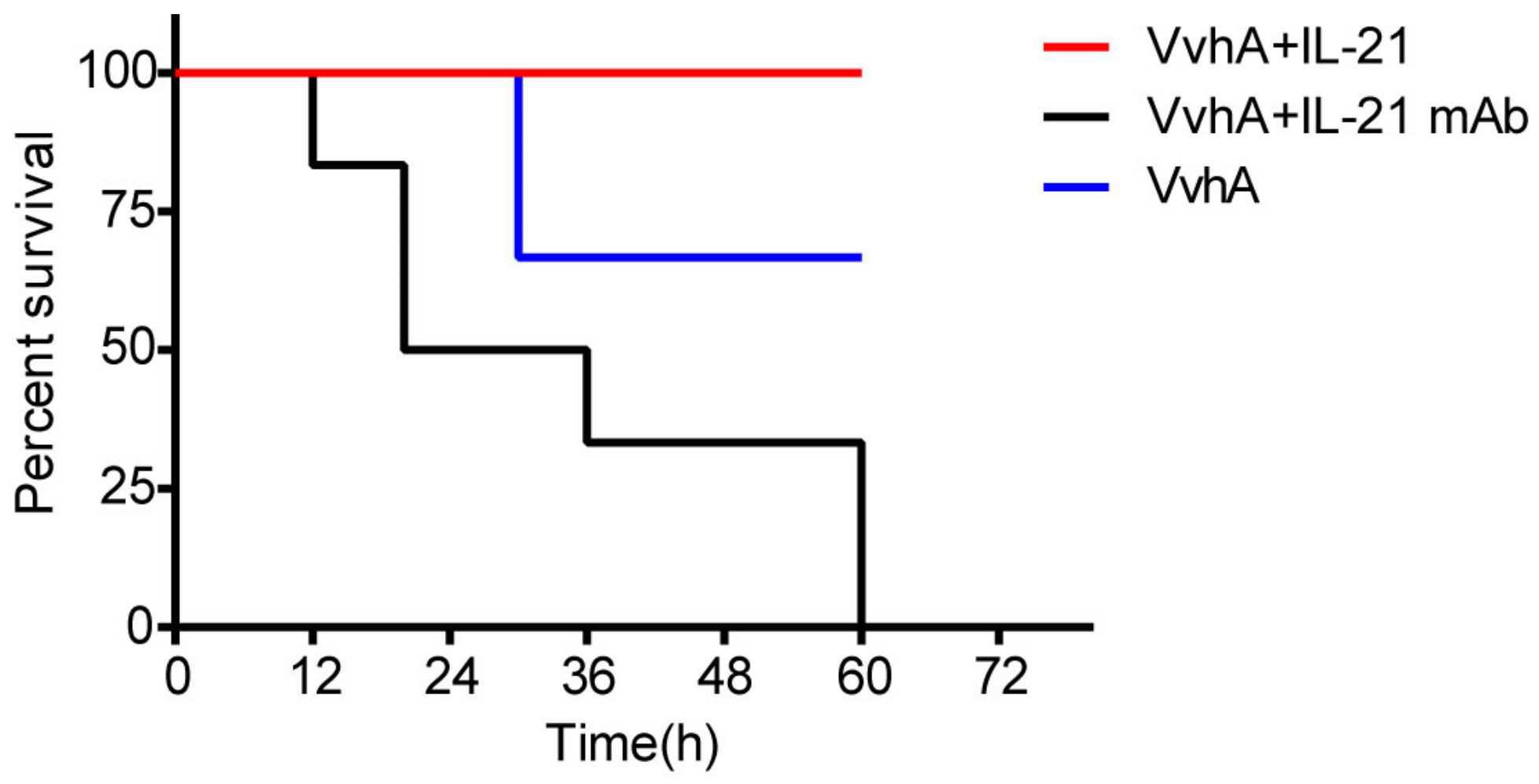

Figure 1 
Survival curve of mice. The survival rate of mice was monitored for $72 \mathrm{~h}$ after intraperitoneal injection of V. vulnificus.
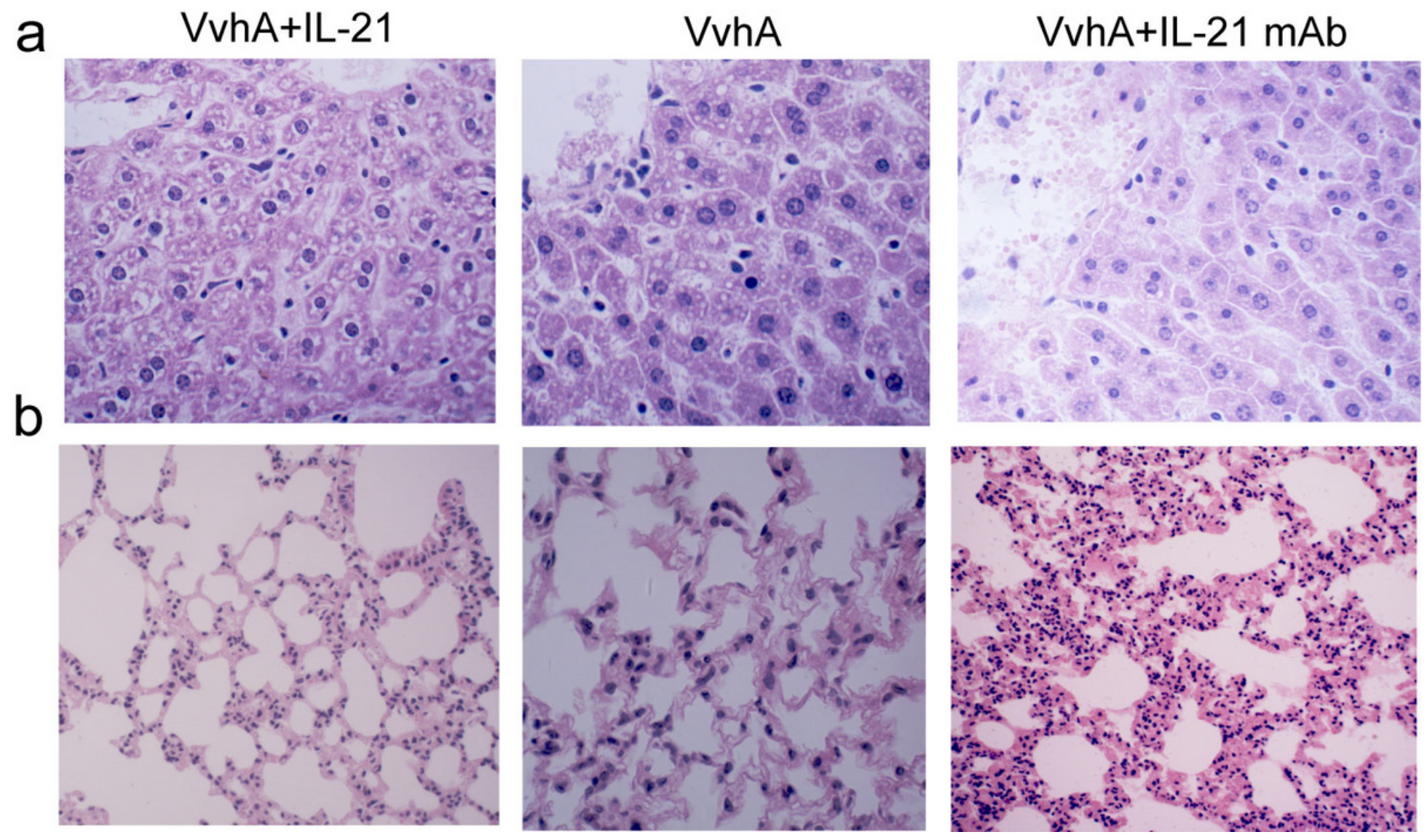

Figure 2

Histopathological evaluation. VvhA-immunized mice treated with IL-21 or IL-21 mAb were euthanized at $72 \mathrm{~h}$ after being intraperitoneally injected with $\mathrm{V}$. vulnificus. Liver and lung sections were stained with $\mathrm{H}$ \& E. (a) Hematoxylin and eosin (H\&E)-stained liver sections ( $\times 400)$. (b) H\&E-stained lung sections $(\times 400)$. 


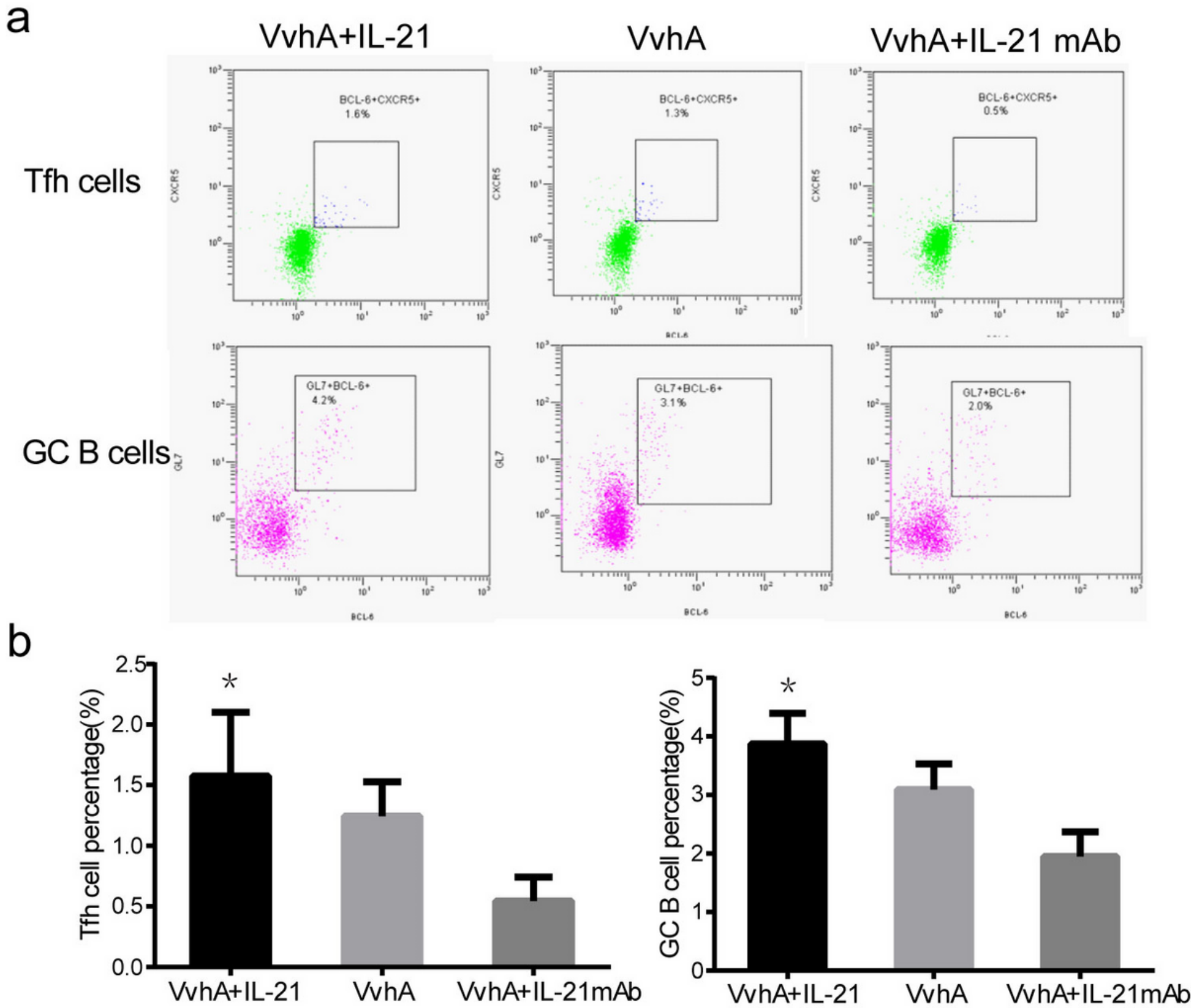

Figure 3

Immune response of Tfh cells and GC B cells in the lymph node cells from VvhA-immunized mouse analyzed by flow cytometry. (a) The percentage of Tfh cells in total CD4+ cells and the percentage of GC B cells in total B cells. (b) Statistical chart of Tfh and GC B cells in VvhA-immunized mice. Data are expressed as the mean $\pm S D(n=5)$. ${ }^{*}<0.05$ compared with the VvhA and VvhA+IL-21 mAb groups. 


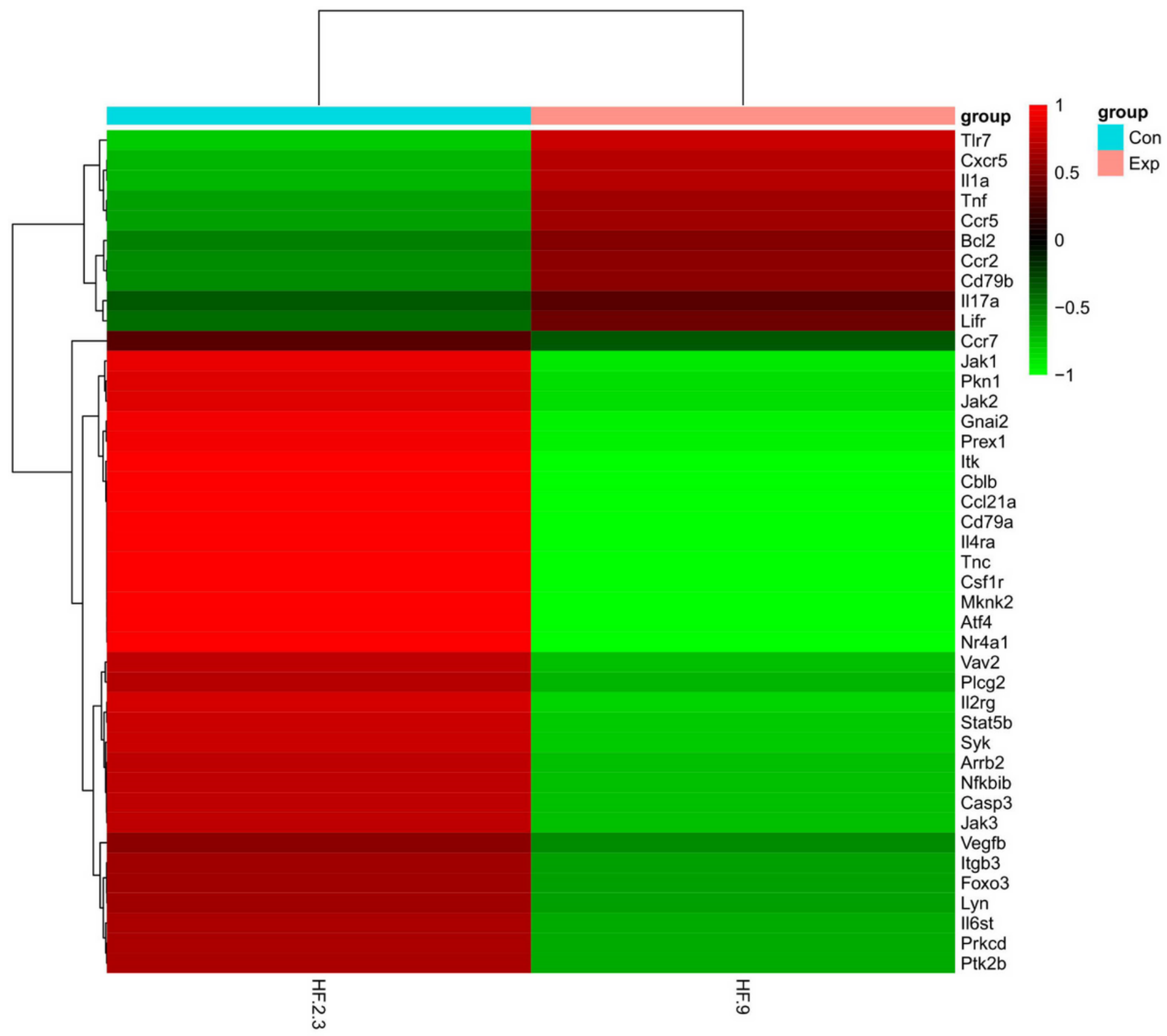

\section{Figure 4}

Hierarchical clustering of 40 genes (fold change $>2.0, \mathrm{P}<0.05$ ) altered by IL-21 in mouse lymph node cells. The horizontal axis represents the sample names between groups, blue represents the VvhAimmunized mice, and pink represents the upregulated IL-21 in VvhA-immunized mice. The vertical axis represents the differentially expressed genes. Red represents high expression of the differentially expressed genes, and green represents low expression of differentially expressed genes. Statistically significant differences between the VvhA-immunized mice and upregulated IL-21 in VvhA-immunized mouse groups are indicated by $\mathrm{P}<0.05$. 
a

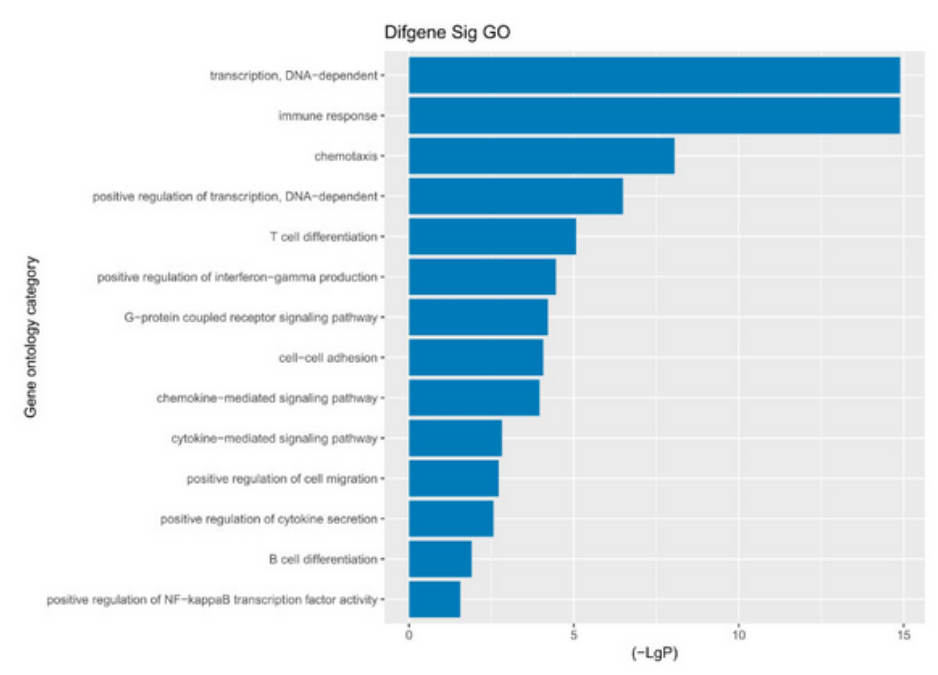

$\mathrm{b}$

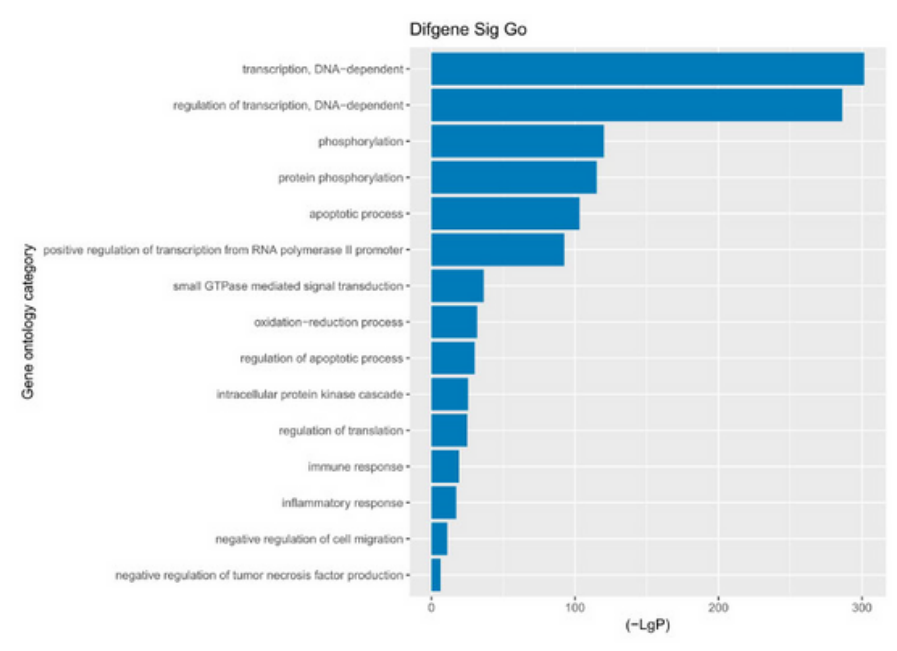

\section{Figure 5}

GO analysis of differential genes. (a) GO analysis of upregulated differential genes. (b) GO analysis of downregulated differential genes. The vertical axis is the GO category, and the horizontal axis is the log of the $\mathrm{P}$ value (-LgP).

a

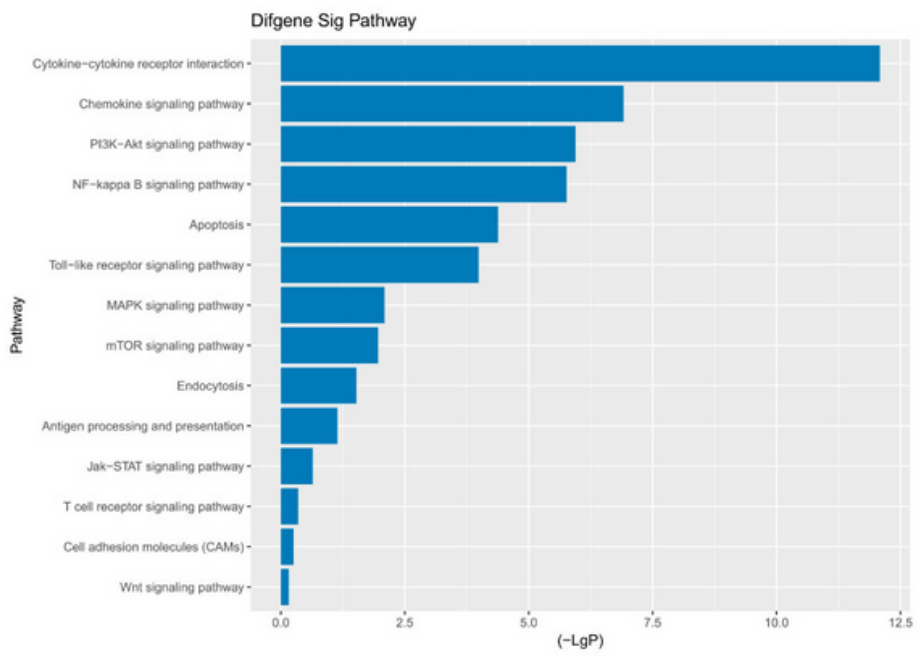

b

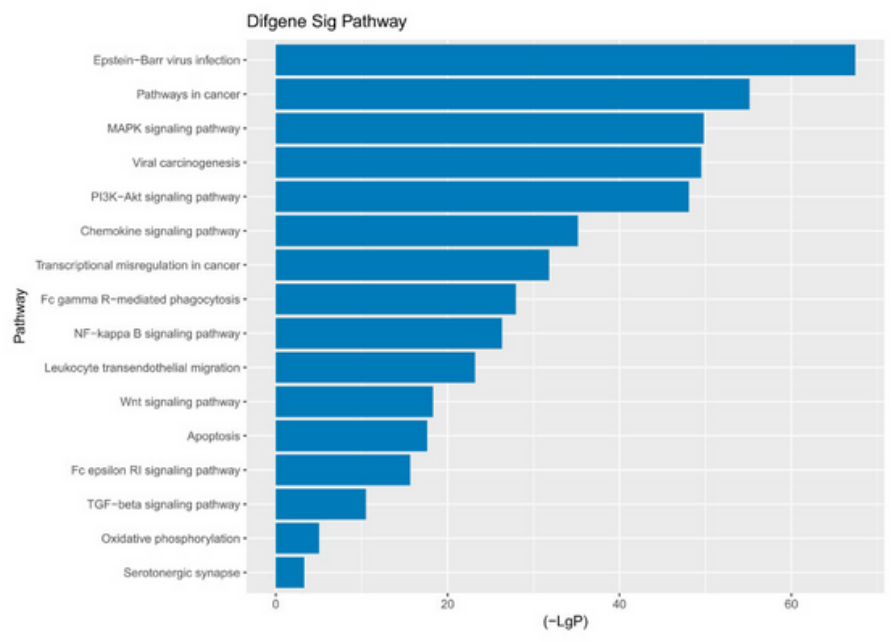

\section{Figure 6}

Pathway analysis of the differentially expressed genes. (a) Pathway analysis of upregulated genes. (b) Pathway analysis of downregulated genes. The vertical axis is the pathway, and the horizontal axis is the log of the $P$ value (-LgP). 


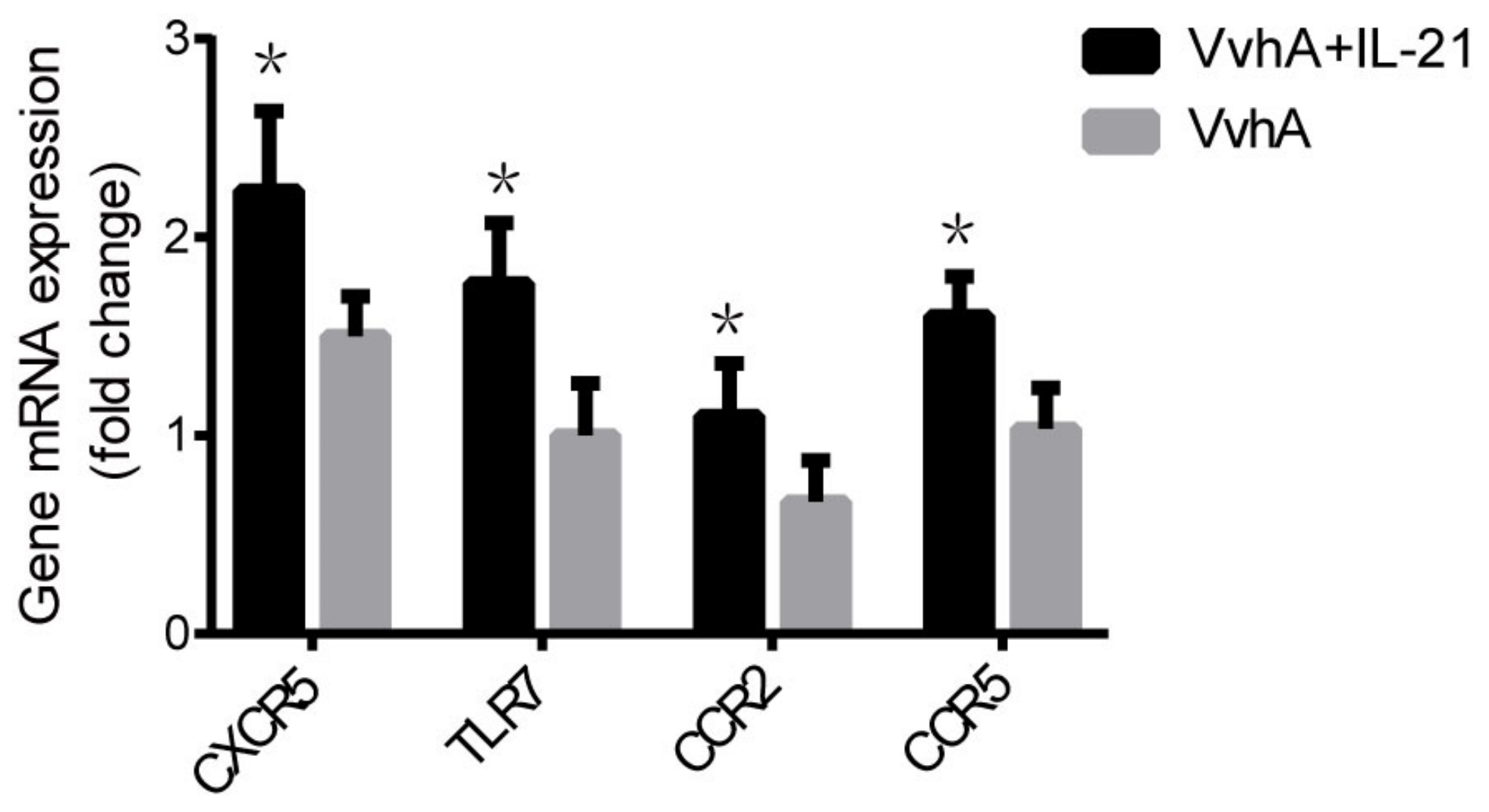

Figure 7

RT-qPCR analysis of gene expression in mouse lymph node cells. VvhA-immunized mice were treated with IL-21, and the total RNA was extracted from the lymph node cell. The gene expression was analyzed using the SYBR green RT-qPCR method. Data (fold change) are expressed as mean $\pm S D(n=3) .{ }^{*}<0.05$ compared with the control group. 